\title{
CONSOLIDATION OF URBAN VILLAGE SETTLEMENT PATTERNS USING HYBRID ARCHITECTURE CONCEPT APPROACH (Case Study: Densely Populated Settlement Of Sindulang Satu Village, Manado)
}

\author{
Adrianus Leo Liem ${ }^{1 *}$, Budi Prayitno ${ }^{2}$ \\ ${ }^{1,2}$ Departemen of Architecture and Planning, Universitas Gadjah Mada, Yogyakarta, Indonesia \\ *Corresponding author; Email: adrianusleoliem@gmail.com
}

\begin{abstract}
The hybrid concept that develops in urban community settlements in an unplaning manner has led to various forms of settlement patterns that are adapted to social, economic and environmental conditions. This hybridity condition is potential for more innovative settlement consolidation efforts. This research was conducted to examine the quality of the hybridity formed in urban village settlements in Sindulang Satu Village, Manado, and to find the consolidation principle of settlement patterns by developing hybridity values at the site location. The quality of the hybridity was examined based on the perspective of programming hybrid, operational hybrid and spatial hybrid. This study used a qualitative research method, with modeling and experimental simulation technique approach. The analysis of settlement space performance was done by statistical calculations and graphical analysis using space syntax method. The research data was obtained using questionnaire, interviews and observations methods of samples that met the criteria of purposive sampling. The results of this study showed the potential of the hybridity in site locations with good quality, so that it became a consideration in formulating the principle of settlement pattern consolidation to increase site hybridity.
\end{abstract}

Keywords: Consolidation; settlement pattern; hybrid concept.

\section{INTRODUCTION}

The impact of urbanization has resulted in an increase in population density in urban areas (Muhi, 2012). According to the Prospect of World Urbanization through the United Nations (UN) agency in $2014,54 \%$ of the world's population lives in urban areas, and is expected to increase to $66 \%$ by 2050 . In Asia, the current urban population increase reaches $48 \%$, which is projected that there will be a rapid population growth of up to $64 \%$ by 2050 (Cho, Heng, \& Trinic, 2016).

The main challenge of urban design today is creating or re-creating good urban space with the ability to accommodate and respond to diverse, intense, hybrid and dynamic urban conditions (Cho, Heng, \& Trinic, 2016). As part of this demand, the provision of good settlement space with quality housing and public space conditions is seen as one of the keys to maintain environmental and social sustainability of the community which can improve the quality of life in the current urban environment (Amin, 2006). This refers to the evaluation of spatial conditions, including the estimates of the number of people in space, availability of space and spatial arrangements (Cheng, 2010), as processes formed by the cognitive experience and socio-cultural background of the users (Alexander, 1993; Malnar, \& Vodvarka, 2004). In cities with high intensity of spatial density, Uytenhaak (2008) stated that overall density resulted from the number, diversity, closeness and intensity of the users, structure and infrastructure, as well as urban movements and activities.

As general problem of high density levels in big cities in Indonesia, high density levels also occur in Manado City, one of the subdistricts that are classified as dense is Tuminting Subdistrict, the high density impacts on the settlement environment that is formed where there is a significant reduction in land (Communication and Information Service of Manado City Government, 2017).

The increase of population density and urban population is a worldwide trend, so this problem receives a lot of attention in contemporary academic research and discussion, especially those that refer to its high impact on environmentally and socially friendly urban development (Cho, Heng, \& Trinic, 2016).

The hybrid concept is a concept that develops in unplaning community settlements, so that in its development, it has led to various forms and types of settlements that are adapted to the social, economic and environmental conditions of the housing, an important aspect that can be utilized in the consolidation efforts.

\section{LITERATURE REVIEW}

\section{Hybrid Concept}

According to Joseph Fenton (1985), the concept of hybrid architecture and hybrid power comes from 
genetics, referring to the cross-development of different species to reinforce certain characteristics of new hybrid species. However, this process has the possibility of a risk of various mixing that occurs, which can lead to conflict (failure) and also the consistency of false space. In line with that, Kurokawa (1991) said that hybrid means to combine or mix various best elements from different cultures, both between the culture of the present and the past (diachronic), or between the culture of the present (synchronous).

The hybrid concept basically seems unpredictable, has various relationships between aspects in it, always encourages co-existence, and realizes that unplanned situations are an important part of sustainability that occurs (Mozas, 2014).

According to Cho, et al. (2013), in their theory of Hybrid Urban Space, there are three categories of hybrid models, which are; spatial hybrid, programmatic hybrid, and operational hybrid. Spatial hybrid is reflected through structural complexity, technological innovation, and its relationship with surrounding contexts that form new spatial conditions for access, connectivity, physical flexibility and innovative public uses. Programmatic hybrid is a combination of various activities that work together and are compatible with the use of unconventional space. Flexible and multifunctional programming are several mechanisms that are driven for the purpose of maximizing the use of space and serving all groups. Operational hybrid model refers to new conditions for spatial negotiations by redefining conventional definition of spatial constraints and accessibility by spatial negotiations, temporary use, optimizing safety, and also space management.

\section{Settlement Spaces and Consolidation Concepts}

Forming elements of urban space patterns basically consist of elements of space covered by buildings (solid) and open spaces (voids), which is also stated in the figure-ground theory by Markus Zahn (1999). The figure-ground theory is a study of the comparative relationship between land covered by buildings as a solid mass (figure) and open (ground) spaces (voids).

In addition to building mass as a physical form of community housing within the village area, outdoor space is an important spatial aspect in supporting social activities and interactions for the community. According to Nugroho A.C (2010), most of the open space in the village are an open space type of path/corridor (street), which also functions as nodes, and become points that have potential both in village structuring character and efforts. Prayitno
(2013) argued that one of the physical forms of shared space in the context of urban villages in Indonesia is the presence of village alley and pocket open space. The village alley gives residents the opportunity to meet each other, because when the door and window are opened, people who cross the alley and pocket open space can easily see inside the house. Whereas pocket open space is not only used as a space for social activities but also used as a space for informal activities that includes service and retail activities.

Within the scope of the settlement study, the view of consolidation was also expressed by Prayitno (2017), according to him, the spatial pattern consolidation activity, in this case meant the village spatial pattern, is by utilizing/using existing potential to produce new patterns and more collective spatial diversity. This consolidation activity/effort is actually a form of finding ideal conditions that have better quality than the initial consolidated form. The consolidation effort is a step to re-structure and strengthen the spatial setting system in the degraded areas, both the spatial and ecological conditions. According to Prayitno (2012), the basic principles regarding consolidation include; realignment of regional space, securing rights to regional space, honest procedures, and community participation.

\section{RESEARCH METHODS}

This research was conducted using qualitative methods, with modeling and experimental simulation technique approaches to the configuration of settlement space. Qualitative research method was used at the stage of identifying the potential and quality of hybridity on the existing site conditions, then proceed to the stage of model simulation of the site configuration. Quantitative approach was also used as an approach to measure the qualitative data and the data from modeling simulations, as well as experimental stages for the purpose to discover the principle of consolidation.

\section{Research Component}

The research component in this study consisted of independent and dependent variables. The independent variables were the solid element and the void element. While the dependent variables were related to the elements forming hybridity.

\section{Research Location}

The research location was in Manado City, North Sulawesi Province. The location of the selected site was in the Sindulang Satu Village, Manado, 
which is administratively part of the Tuminting Subdistrict, Manado City (Fig. 1). In the administrative map of Sindulang Satu Village, the selected site covered the Environmental Area 4 as a whole and part of the Environmental Area 2. The selected location was a densely populated settlement with land conditions of $\pm 90 \%$ covered by buildings and the rest was open space

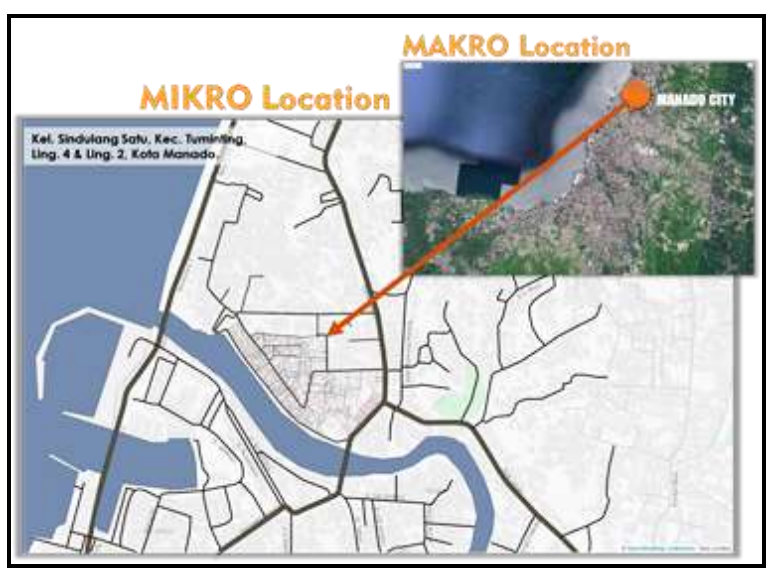

Fig. 1. Research location (Source: Google earth, analysis, 2019).

\section{Research Tools}

This study also used software as a support tool to find the syntax value of the existing site configuration and alternative model of the site configuration presented. The software used in this study was depthmap software of depthmapxnet 0.60 version.

\section{Data Processing Strategy}

This study used a statistical approach and graphical analysis to measure the performance of space in the site configuration as well as an alternative model of site configuration presented. In statistical calculations for space performance analysis, the spacial performance categories were divided into five categories based on interval scales, which were; very low, low, medium, high, and very high.

\section{DATA ANALYSIS}

In understanding the activities and physical picture of the space cross-section profile of the site location, a grouping of spaces was carried out to facilitate an assessment of the carrying capacity of the space and the perception of residents who occupy the site. The grouping of spaces was done by considering the characteristics of the site location and the road lane within the site location. The grouping of spaces within the site location was divided into 6 groups of spaces shown in Fig. 2.

\section{Analysis of Spatial Performance and Correlations between Aspects}

To understand the quality of hybridity being discussed, an assessment of the performance of the space was done by measuring several parameters, which were; (1) the level of intensity of the space users, (2) functional programs that have an impact, (3) the achievement of the space, and (4) the comfort and security of access points for the users in space (Table 1). Measurement of the spatial performance related to the four parameters above was done by processing the questionnaire results to determine the perceptions of the space users in the existing site location, then scoring stage was performed for each parameter to obtain the mode and median values that describe the performance of the space according to the map division on the site location (Fig. 2). The next stage was to analyze the correlation between these aspects using the Spearman Correlation Rank method (Table 2)

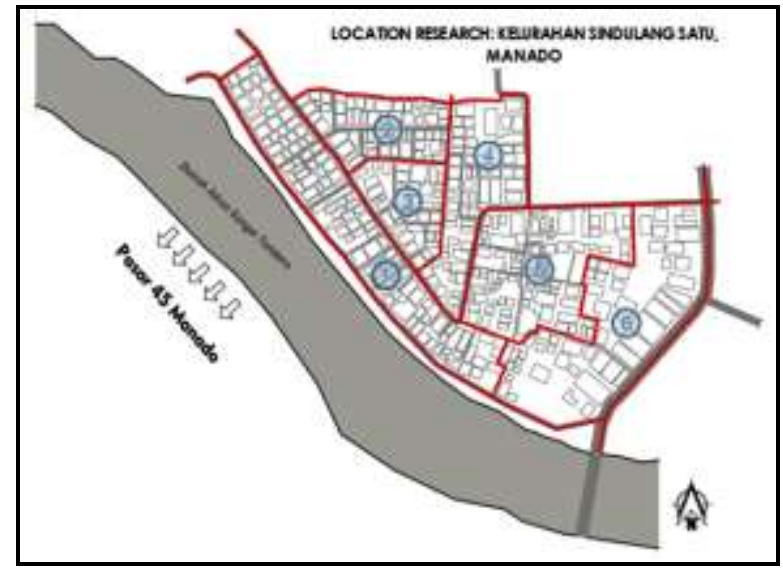

Fig. 2. Classification of the spaces in the site location (Source: Analysis, 2019).

\section{Space Syntax Analysis}

The space syntax analysis stage was the stage of analysis of spacial performance using the axial map of the configuration of the existing site location to measure the connectivity value, integration value, mean depth value and global intelligibility value. In this analysis phase, the outputs that were considered were data about the global average value of each existing syntax values. The data about the syntax values generated were in the form of connectivity, integration, mean depth, and intelligibility syntax values. The measurement results were shown in Fig. 3 and Table 3. Based on the results of the graphical analysis of the existing axial site location map, the calculated $\mathrm{R}$ value obtained was 0.7172161459 . The $R$ value was the value of global intelligibility which 
Table 1. Measurement of space performance

\begin{tabular}{|c|c|c|c|c|c|}
\hline \multirow{2}{*}{ No } & \multirow{2}{*}{ Research Parameters } & \multirow{2}{*}{ Max } & \multirow{2}{*}{ Min } & \multicolumn{2}{|c|}{ Category } \\
\hline & & & & Mode & Median \\
\hline & $\begin{array}{l}\text { The Level of intensity of the space } \\
\text { users }\end{array}$ & $\begin{array}{c}\text { Space 1 } \\
(\text { Score 522) }\end{array}$ & $\begin{array}{c}\text { Space } 5 \\
(\text { Score } 180)\end{array}$ & $\begin{array}{c}\text { High } \\
(37,13 \% \mathrm{~s} / \mathrm{d} 41,61 \%)\end{array}$ & $\begin{array}{c}\text { High } \\
(71,38 \%)\end{array}$ \\
\hline 2. & $\begin{array}{l}\text { Functional programs that have an } \\
\text { impact of site location }\end{array}$ & $\begin{array}{c}\text { Space 1 } \\
(\text { Score 522) }\end{array}$ & $\begin{array}{c}\text { Space } 5 \\
(\text { Score } 153)\end{array}$ & $\begin{array}{c}\text { Mid } \\
(44,58 \% \mathrm{~s} / \mathrm{d} 47,48 \%)\end{array}$ & $\begin{array}{c}\text { Mid } \\
(54,13 \%)\end{array}$ \\
\hline & The achievementof the space & $\begin{array}{c}\text { Space } 1 \\
(\text { Score 507) }\end{array}$ & $\begin{array}{c}\text { Space } 4 \\
(\text { Score } 204)\end{array}$ & $\begin{array}{c}\text { Mid } \\
(39,66 \% \mathrm{~s} / \mathrm{d} 41,925)\end{array}$ & $\begin{array}{c}\text { Mid } \\
(51,59 \%)\end{array}$ \\
\hline 4. & $\begin{array}{l}\text { The comfort and security of acess } \\
\text { points for the users in space }\end{array}$ & $\begin{array}{c}\text { Space } 1 \\
(\text { Score 519) }\end{array}$ & $\begin{array}{c}\text { Space } 4 \\
(\text { Score } 234)\end{array}$ & $\begin{array}{c}\text { Mid } \\
(71,51 \% \mathrm{~s} / \mathrm{d} 73,57 \%)\end{array}$ & $\begin{array}{c}\text { Mid } \\
(72,54 \%)\end{array}$ \\
\hline
\end{tabular}

Source: Analysis, 2019

Table 2. Correlation analysis between aspects

\begin{tabular}{|c|c|c|}
\hline No & Correlation between & Annotation \\
\hline 1. & $\begin{array}{l}\text { The Level of intensity of the space users, and functional programs that have an impact } \\
\text { of site location }\end{array}$ & $\begin{array}{c}\text { Strong Correlation }(+) \\
r^{\prime}=0,7143>0,6571\end{array}$ \\
\hline 2. & The Level of intensity of the space users, and the achievementof the space & $\begin{array}{l}\text { Weak Correlation }(+) \\
r^{\prime}=0,2572<0,6571\end{array}$ \\
\hline 3. & $\begin{array}{l}\text { The Level of intensity of the space users, and the comfort and security of acess points } \\
\text { for the users in space }\end{array}$ & $\begin{array}{l}\text { Weak Correlation }(+) \\
r^{\prime}=0,60<0,6571\end{array}$ \\
\hline 4. & $\begin{array}{l}\text { The achievementof the space, and the comfort and security of acess points for the users } \\
\text { in space }\end{array}$ & $\begin{array}{l}\text { Strong Correlation }(+) \\
\quad r^{\prime}=0,60<0,6571\end{array}$ \\
\hline 5. & $\begin{array}{l}\text { The achievementof the space, and functional programs that have an impact of site } \\
\text { location }\end{array}$ & $\begin{array}{l}\text { Strong Correlation }(+) \\
r^{\prime}=0,7715>0,6571\end{array}$ \\
\hline 6. & $\begin{array}{l}\text { The comfort and security of acess points for the users in space, and Functional } \\
\text { programs that have an impact of site location }\end{array}$ & $\begin{array}{l}\text { Strong Correlation }(+) \\
r^{\prime}=0,9429>0,6571\end{array}$ \\
\hline
\end{tabular}

Source: Analysis, 2019.

was a correlation between the value of connectivity and the value of integration $(\mathrm{HH})$ from the measurement of the existing site location. The value of $R$ (correlation) was obtained by calculating the root value of $\mathrm{R}^{2}$ (coefficient of determination) (Hillier, 2007; Hillier \& Hanson, 1984). The R value of the measurement results of the space in the existing site location showed good results with the meaning that; the spatial configuration patterns in the existing site location had good spatial clarity, so that they could be easily understood by the space users, but could also be maximized by interfering the existing space configuration patterns.

\section{DISCUSSION: HYBRIDITY QUALITY OF THE EXISTING SITE}

\section{Hybrid Programing in the Existing Site Location}

Based on the analysis results of the level of intensity of the space users in the existing site location, it was globally spread between the "low" to "very high" categories. The level of intensity of the space users globally in the existing site location had an average value of $72 \%$ (the score was 744) and was categorized as "high", which was a potential that was very possible for the development of the concept of hybridity. Conceptually, the ideal conditions for the development of the hybridity concept being discussed are the distribution of level of intensity which is good or in the average category of "high" of the level of intensity, even more. In the existing site conditions, some spaces in the site location, especially those that were not traversed by environmental roads and were located in areas that were quite difficult to reach, had a low level of intensity of the space users with a percentage of about $20.79 \%$ (the score was 393).

One of the most influential functional programs was related to economic functions in the river banks in the site location, which was in space 1 (Fig. 4), with the highest percentage level of $27.62 \%$ (the score was 522 ) and included in the category of "very high". The average value for the measurement of the functional programs that affected the region globally was included in the category of "medium" with a percentage of $54.13 \%$, this showed that there were functional programs and economic activities in several spaces in the site location with a high percentage level and it had an influence on the use of space as well as the form of functional integration that exist within the site location (Fig. 5, Fig. 6 and Table 4). 


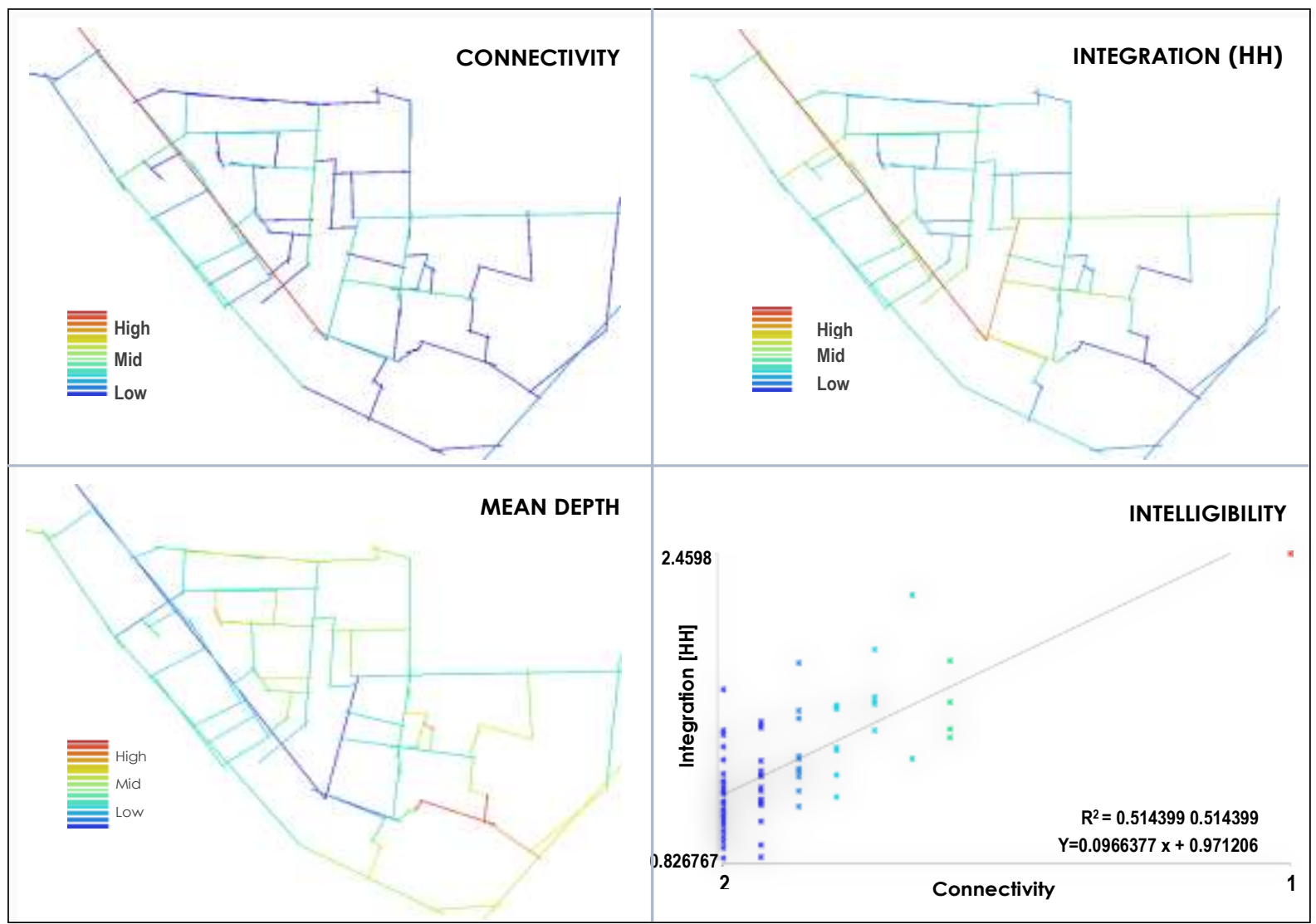

Fig. 3. Measurement of the syntax space of the existing site location; (a) Connectivity, (b) Integration, (c) Mean depth, and (d) Intelligibility (Source: Analysis, 2019).

Table 3. Results of measurement of syntax space of the existing site location

\begin{tabular}{clcccc}
\hline No. & Atribute & Min & Average & Max & R Value \\
\hline $\mathbf{1}$ & Connectivity & 2 & 3,6962 & 17 & - \\
$\mathbf{2}$ & Integration $(\mathrm{HH})$ & 0,826767 & 1,3284 & 2,4598 & - \\
$\mathbf{3}$ & Mean Depth & 2,55128 & 4,01363 & 5,61538 & - \\
$\mathbf{4}$ & Intelligibilit y & - & - & - & $0,717256\left(\mathrm{R}^{2}=514399\right)$ \\
\hline
\end{tabular}

Source: Analysis, 2019.

Activity Generator in Site Location

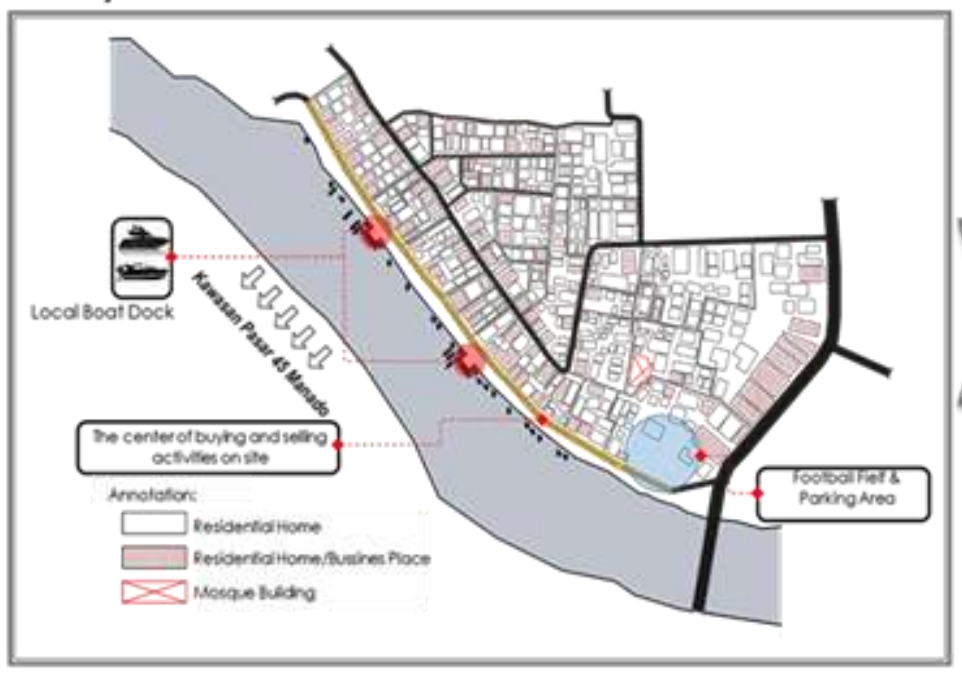

Impoctful Activity
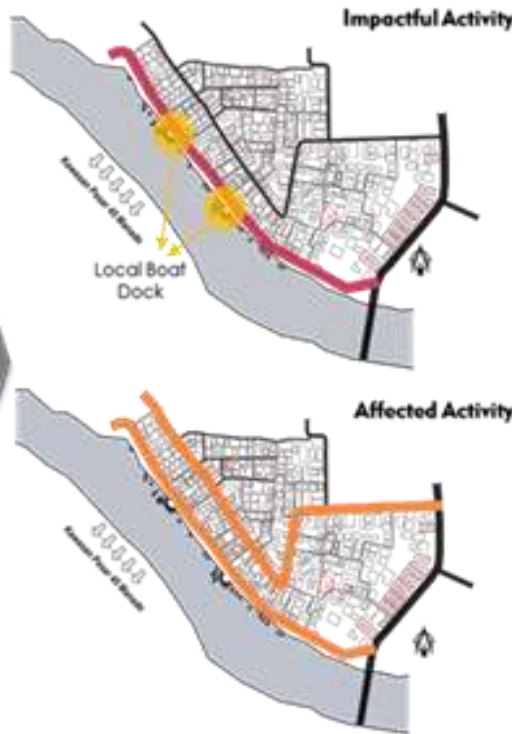

Fig. 4. (a) Nodes of generator of activities in the site location, (b) Impacting activities, (c) Affected space (Source: Analysis, 2019). 


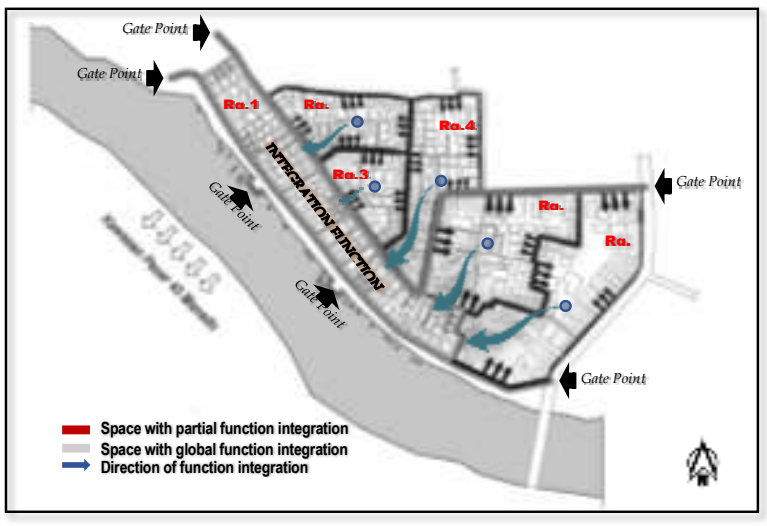

Fig. 5. Form of functional integration in site location (Source: Analysis, 2019).

Table 4. Quality of hybridity based on aspects of programming hybrid

\begin{tabular}{ccccc}
\hline $\begin{array}{c}\text { Name of } \\
\text { Space }\end{array}$ & $\begin{array}{c}\text { Intensity of } \\
\text { the space } \\
\text { users }\end{array}$ & $\begin{array}{c}\text { Users } \\
\text { scale }\end{array}$ & $\begin{array}{c}\text { Form of } \\
\text { function } \\
\text { integration }\end{array}$ & $\begin{array}{c}\text { Functional } \\
\text { programs that } \\
\text { have an impact }\end{array}$ \\
\hline Space 1 & very high & inter & global & very high \\
Space 2 & high & intra & partial & high \\
Space 3 & high & intra & partial & mid \\
Space 4 & mid & intra & partial & mid \\
Space 5 & low & intra & partial & low \\
Space 6 & low & intra & partial & mid \\
\hline
\end{tabular}

Source: Analysis, 2019

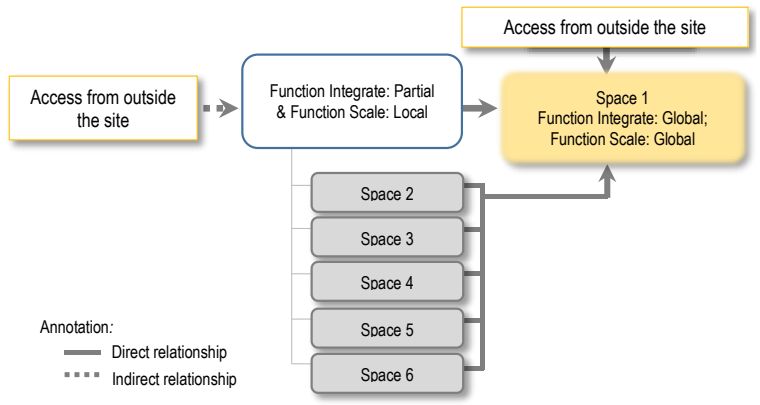

Fig. 6. Schema of form of the functional integration in the site location (Source: Analysis , 2019).

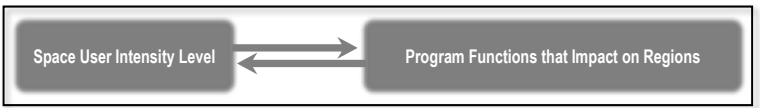

Fig. 7. Correlation between the level of intensity of the users and functional programs that have an impact on the region (Source: Analysis, 2019).

Based on the results of the correlation analysis between the level of intensity of the space users and the space with functional programs that affected the region, there was a strong correlation between the two aspects (Fig. 7). The results of this analysis also showed that, for spaces within the site that were considered to have higher functional value (economic functions), it also influenced the level of intensity of the users in it, in other words to create better hybridity conditions at the site location, it must also present good functional programs and be a regional branding.

\section{Operational Hybrid in the Existing Site Location}

Hybridity in the perspective of operational hybrid is more directed in the form of re-definition of spatial conditions to the conventional understanding of space in terms of spatial constraints and accessibility by spatial negotiations, temporary use of space and forms of space management. This is reflected in the existence of more dynamic spatial conditions, where one of the factors that is the main indication of this problem is related to the availability of very limited space, with high density.

In the physical condition of the space in the site location, the more dynamic use of shared space included the use of road space and also the front yard of housing in the site location, the dynamic condition of this space formed the pocket interactional spaces for the residents as shared space.

The use of the road as a space for the residents' activities was not limited to activities that should be carried out in public spaces, but more than that, this shared space was also used by the residents to carry out activities that were more informal, such as cooking and washing clothes. The problem of limited land was a trigger for the residents in their activities, where this condition triggered conflicts of activities that were not in accordance with conventional rules in general. The residents' habit of carrying out various private activities on the front yard of their housing (using the road body) also had a good value in the conditions of interaction between the residents that happened within the site location. Under certain conditions, road space was also often used by the residents as space for various community activities, such as holding parties and meetings. This certainly caused the transfer of the function of the road into a space for the residents' activities. From an operational hybrid point of view, this condition showed that the hybridity values that were reflected in the form of the use of space contained in the site location. The form of spatial negotiation in the site location was shown in more detail in the division of space based on the type of space and activity, which was illustrated in Fig. 10. In accordance with the description in Fig. 10, the area of public space in the site location that used the road as a shared space also included semi-public spaces and private spaces there. The existence of private spaces in public spaces was formed because of the activities of the residents who used public space to carry out activities that were more informal. This condition actually showed a fairly high level of 
complexity in the use of space, so that with the form of spatial negotiations that were formed, the use of space in the site location caused the function of the road used as a shared space also became more flexible to accommodate a variety of other activities.

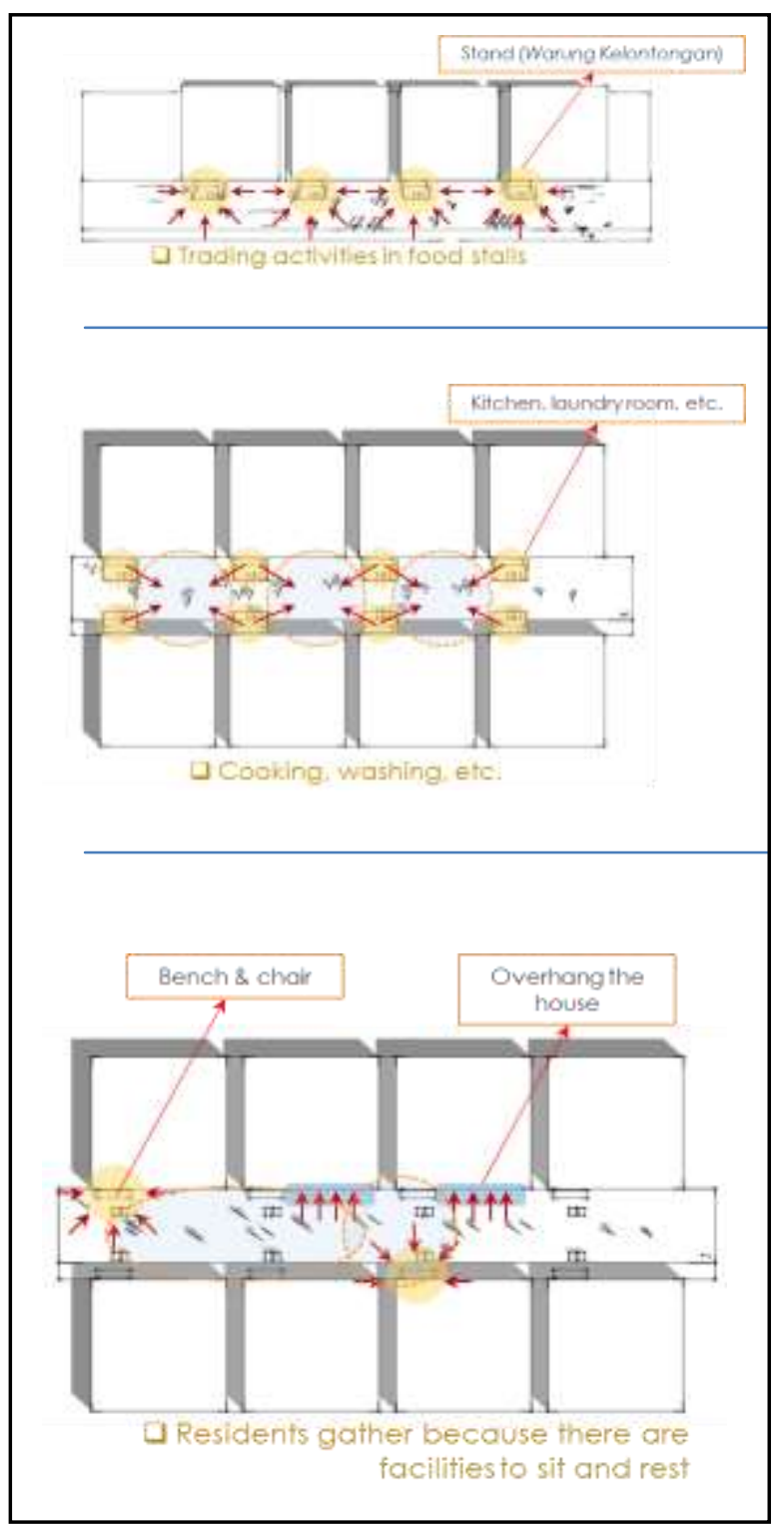

Fig. 8. The process of forming pocket open space in the site location (Source: Analysis, 2019).

Based on the results of observations carried out, spaces with functional programs that were included in the category of "low" to "medium" tend to be spaces that limit their relationship with other spaces, meaning that those spaces did not directly open the access easy for the space users from outside the region. These spaces were usually not traversed by the environmental roads and were only traversed by the residents, so social interactions that tend to occur were limited to interactions between the local residents, in contrast to spaces that had high economic function values, which were more open to more interactions between the residents' area with the users from outside the region, this was explained in Fig. 8 and Fig. 9. Hybridity of the region in the hybrid programming frame was in the form the existing functional integration, which was a space with partial functional integration, impacting on the value of lower space user intensity, compared with other spaces that had the value of the integration characteristics of globally integrated functions.

\section{Spatial Hybrid in the Existing Site Locations}

Hybridity in the perspective of the spatial hybrid aspect is reflected through the complexity of the structure and its relationship to the surrounding context that forms new spatial conditions for access, connectivity, physical flexibility and innovative public uses.

In the existing site conditions, the measurement of the accessibility value considered the value of achievement of the space and the comfort and security of the access point for the users (Fig. 11). The value of the level of achievement of the space globally based on the results of the analysis was included in the category of "medium" and there was still space with the category of "low". Another factor in the consideration of the site location accessibility was related to the level of comfort and security of the space users, which globally, was spread between the "medium" to "very high" categories. In the condition of the site location globally, the level of comfort and security of the space users has an average value of "medium" level of comfort and security of the space.

Based on the analysis of the correlation between the two aspects forming the accessibility being discussed, there was a strong correlation and influence (+) between the level of comfort/security of the space user and the level of achievement of the space, so that by optimizing the level of comfort and security of the access point for the space user, it would have an impact on the value the level of achievement of the space, this also applied vice versa.

Another aspect of spatial hybrid which was a basic factor that was very influential and had the potential to develop hybridity values of the site location was the syntax value of the site configuration pattern, measured by calculating the value of connectivity, integration space and intelligibility. Based on the results, it was obtained the value of the global connectivity in the site location of 3.6963, and included in the category of "very low" compared to the minimum syntax value and the maximum syntax value obtained from the calculations performed. The 


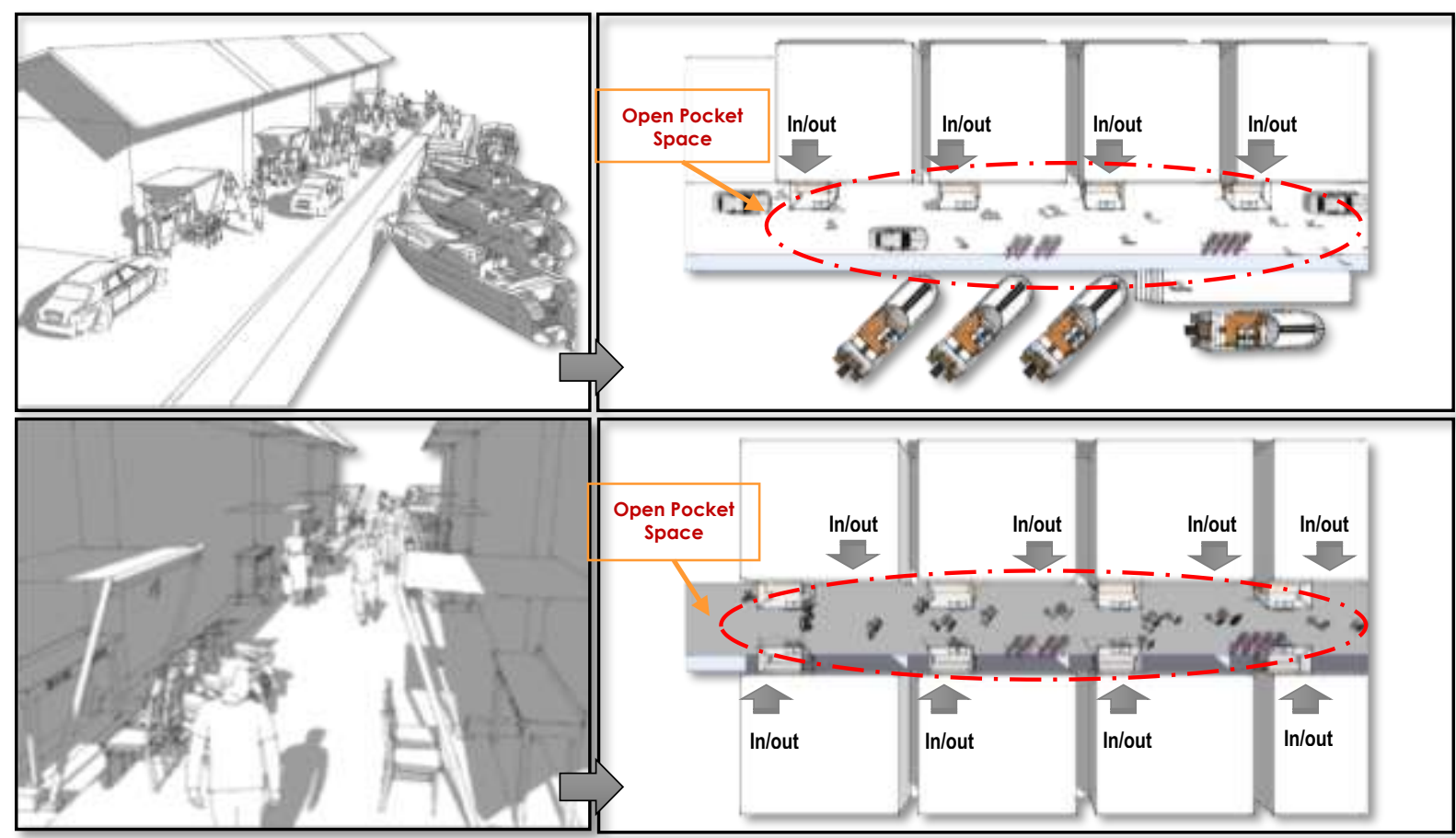

Fig. 9. Physical description of road space utilization for activities in the site location (Source: Analysis, 2019).

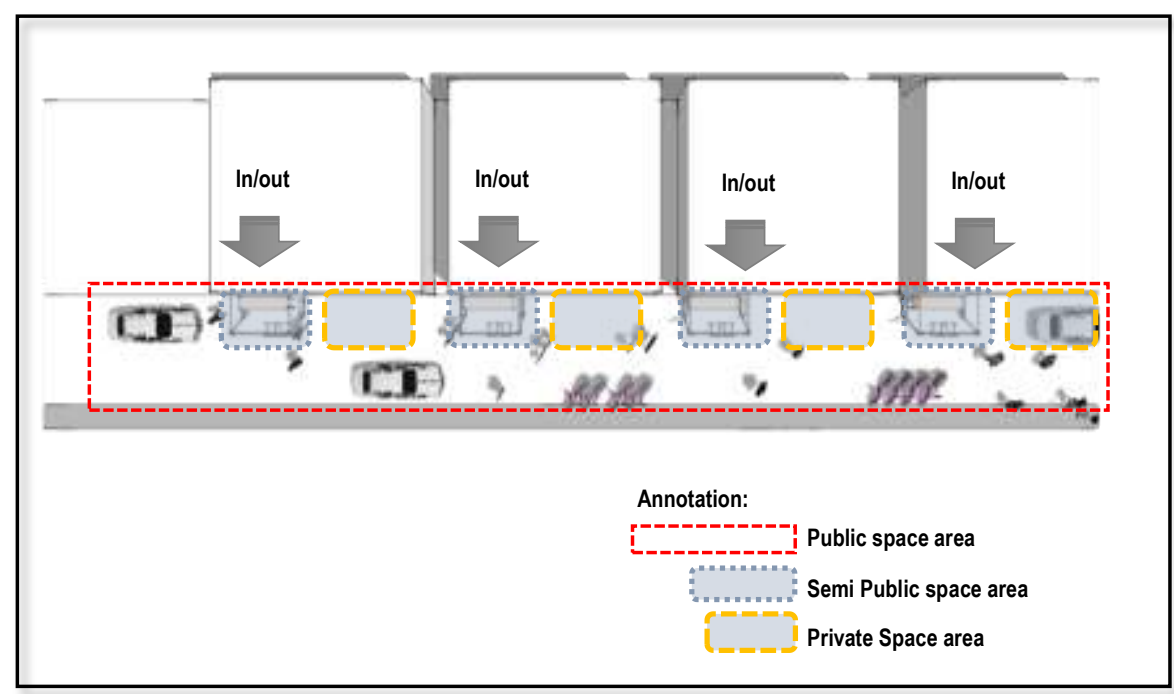

Fig. 10. Spatial arrangements in the use of road bodies based on the type of activity in the site location (Source: Analysis, 2019).

average syntax value for "very low" connectivity was due to the spatial configuration in the location of the site that was not well connected between the existing spaces. Several factors causing the low value of global connectivity because there were still circulation paths that were only connected at two points of the circulation pathway, which in order to increase the value of connectivity, the existing circulation paths should be connected more than 2 (two) lines. In addition, the existence of dead-end paths in circulation (only connected to one circulation path) also caused the low value of global connectivity. The difference in the value of connectivity between spaces in the site location with the gap in the value of connectivity that had not been evenly distributed globally, had an impact on the shape of the character of the space partially, especially spaces with relatively low connectivity values (Fig. 13).

The measurement of the value of global integration syntax in the existing site location had an average value of global integration of 1.3284 , the results of measurement of the average value of global 
integration of the existing site location were classified as "low" compared to the minimum and maximum results of measurement of global integration syntax values. One of the factors influencing the low value of global integration was because the site location configuration pattern had a low connectivity value. The measurement of global integration syntax values in the existing site location showed that there was a tendency of activity orientation in the regional space, in space 1 , space 2 , space 3 , and space 4 (Fig. 12), this became a consideration of the intended consolidation effort.

The syntax value which was very important and very influential to the achievement of hybridity values in the site location was related to the global intelligibility value of the site location. The value of good global intelligibility syntax allowed the space users to better understand the configuration of the existing space. Based on the results of the analysis conducted (Fig. 3), the average value for the intelligibility syntax at the existing site location was 0.7172161459 , this average value was categorized as good (the scale was 0-1), but in the consolidation effort, a modification could still be done to the configuration pattern to get a better global intelligibility value.

Basically, in reviewing the value of global hybridity from the perspective of spatial hybrid aspect, the condition of global hybridity showed that there were still gaps in syntax and accessibility in regional spaces globally, this was because there were still certain spaces with high syntax values, but there were also gaps in other spaces. So that the continuity of hybridity in the site location had been going well with good quality, but could be further improved.

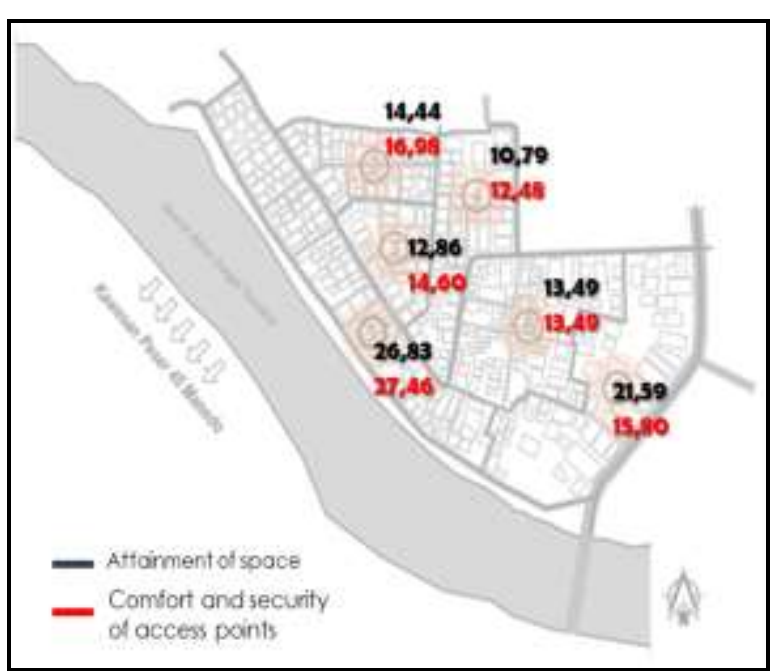

Fig. 11. Percentage of the level of security and comfort of access point users, and the level of achievement in the space (Source: Analysis 2019).

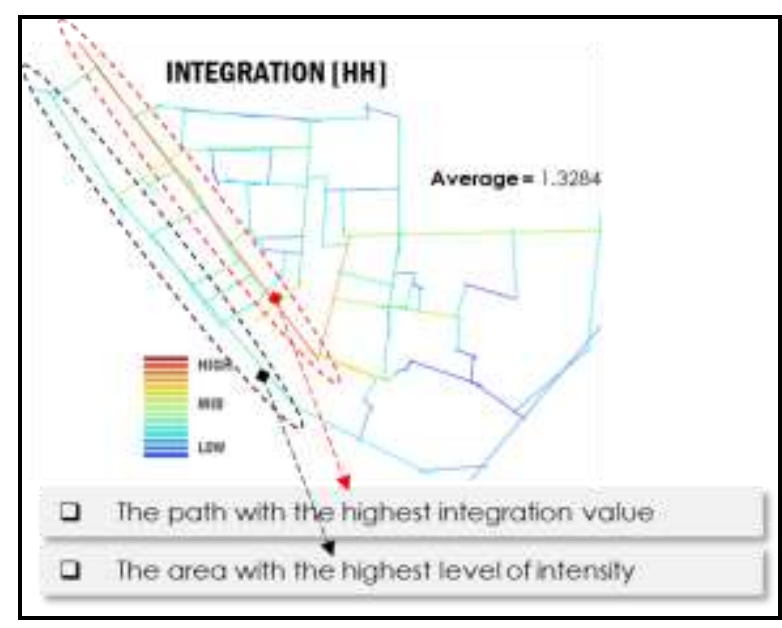

Fig. 12. The area in the site location with the highest integration syntax value (Source: Analysis, 2019).

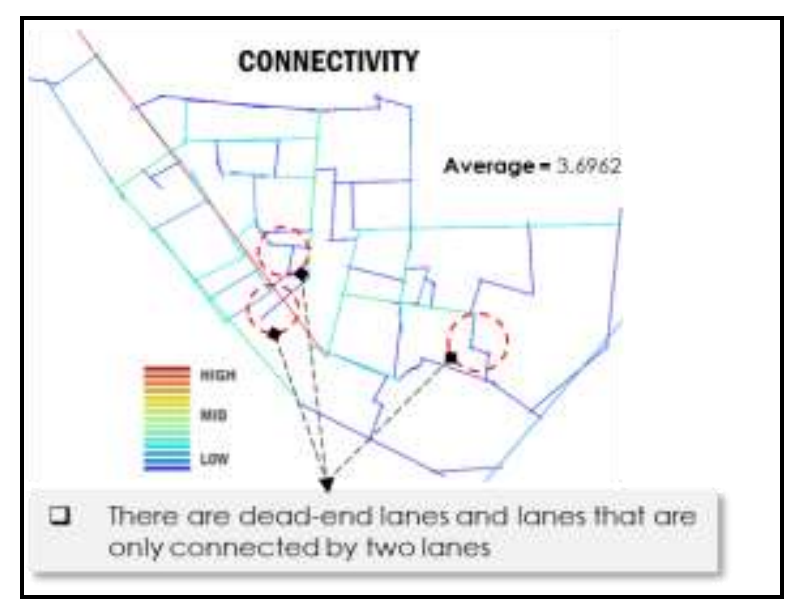

Fig. 13. Potential vulnerability to connectivity conditions in the site location (Source: Analysis, 2019).

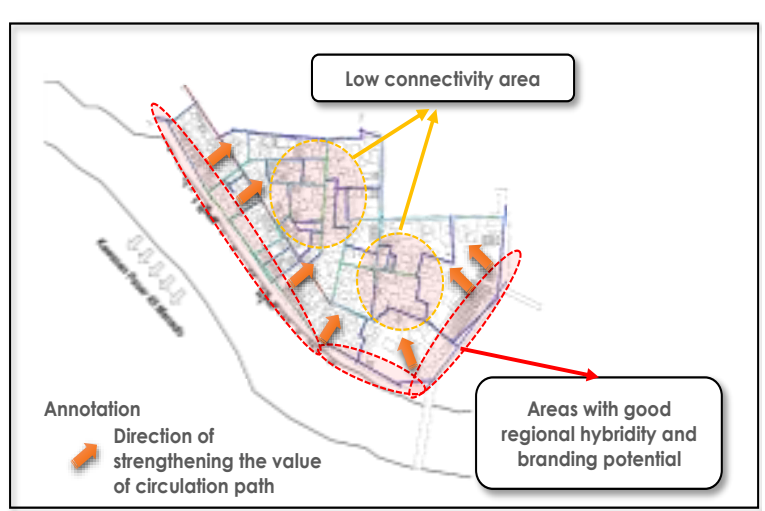

Fig. 14. Consideration of hybridity conditions in the consolidation effort of the site location (Source: Analysis, 2019).

\section{HYBRIDITY CONDITIONS OF THE SITE LOCATION}

A good spatial hybrid condition is the basic framework for the ideal concept of hybridity to take 
place, because the configuration in the spatial hybrid greatly impacts the operational aspects of the hybrid and the programming hybrid in it (Fig. 14).

\section{Consolidation of the Site Configuration Pattern}

Strengthening of site configuration patterns within the region was carried out with the principle of linear open system, with the approach of kampong city block concept. In the intended consolidation effort, it was achieved through two concepts of strengthening the configuration patterns, which were; (1) reducing the presence of circulation pathways with low connectivity values, (2) increasing the site intelligibility value (Fig. 15).

This consolidation effort was also carried out by considering the direction towards the housing blocks, which had an impact on the formation of circulation paths within the site location (Fig. 15), where this was also considered in presenting several alternative site configuration models for testing the syntax values of the alternative site models presented (Fig. 16).

Based on testing on alternative site configuration patterns in a consolidation effort with hybridity approach of the concept in the previous stage, it was

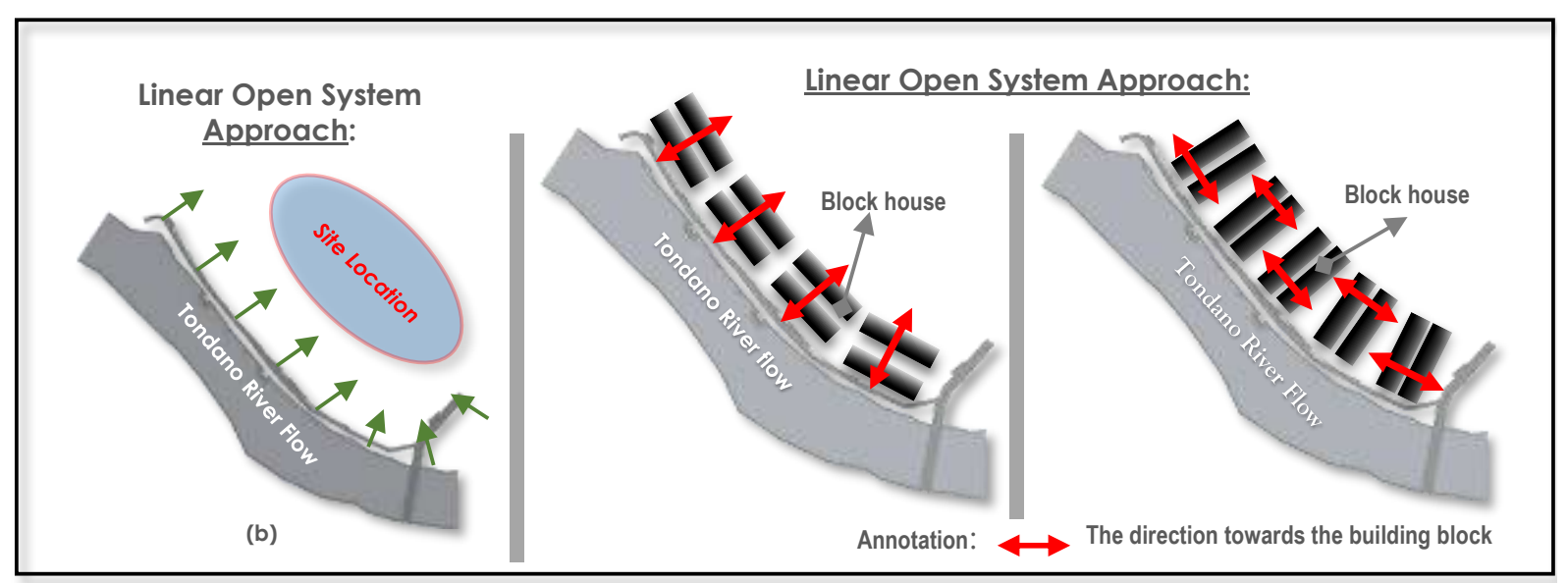

Fig. 15. Linear open system approach and direction toward residential blocks in the consolidation effort of the site location (Source: Analisis, 2019).
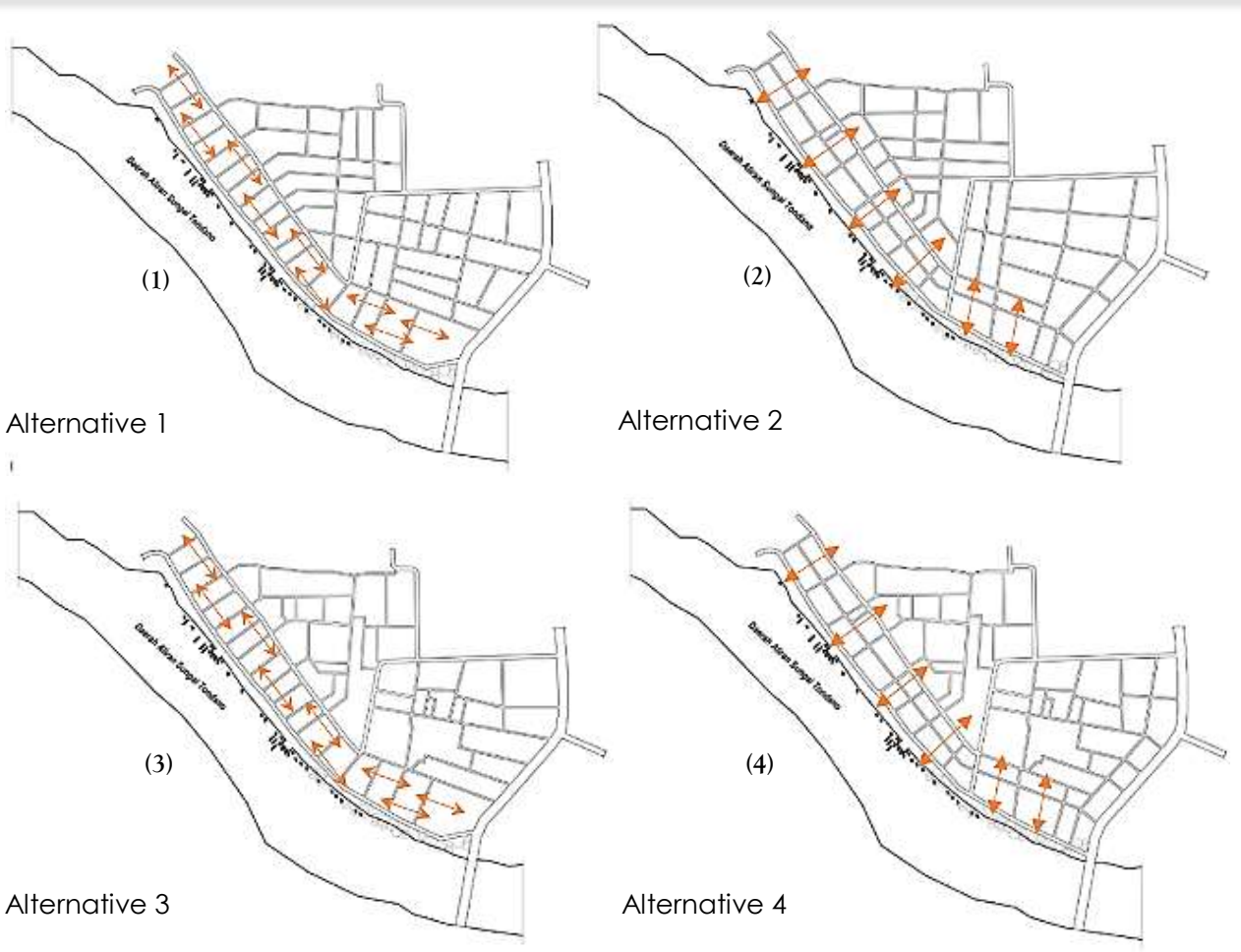

Fig. 16. Alternative model of the site configuration for the consolidation effort of the site (Source: Analysis, 2019). 
Table 5. Recapitulation of Syntax Values based on the Result Test for Alternative Model of the Site Configuration

\begin{tabular}{clcccc}
\hline No & Treadf Model & Connectivity & Integration & Mean Depth & Intelligibility \\
\hline $\mathbf{1}$ & Tapak Eksisting & 3,6962 & 1,3284 & 4,01363 & 0,717256 \\
$\mathbf{2}$ & Alternative 1 & 6,81159 & 2,11867 & 2,79071 & 0,767806 \\
$\mathbf{3}$ & Alternative 2 & $\mathbf{7 , 1 6 4 5 6}$ & $\mathbf{2 , 1 3 5 3 2}$ & $\mathbf{2 , 8 6 6 6}$ & $\mathbf{0 , 8 7 4 9 4 3}$ \\
$\mathbf{4}$ & Alternative 3 & 6,65347 & 1,74248 & 3,50673 & 0,801784 \\
$\mathbf{5}$ & Alternative 4 & 6,37037 & 1,66274 & 3,66719 & 0,813819 \\
\hline
\end{tabular}

found that the highest spatial hybrid performance based on testing on connectivity, integration, mean depth, and intelligibility of the alternative site configuration patterns was on the alternative site configuration pattern 2 .

Intelligibility value of measurement results on Alternative Configuration Model 2 showed the result of 0.874943 (Table 5), this clearly showed the difference in value of the alternatives of other site configuration models. Besides, the performance of this intelligibility value also experienced a significant increase, compared with the intelligibility value from the measurement of the existing site configuration with a value that had an intelligibility value of 0.717256 .

\section{CONCLUSION}

Hybridity conditions in the existing site location in densely populated settlements in Sindulang Satu Village, Manado, had been formed to adjust the physical form of settlement space configuration, which had an impact on the use of space and activities of the residents in the site location.

In the perspective of hybrid programming aspect, the form of functional integration in the existing site location was divided into two forms of functional integration and functional scale, which were the form of global function integration in certain spaces within the site location with diversity and wider scope of functional scope (inter), and the form of partial functional integration in certain spaces in the site location with the diversity and scale of the scope of the function that tends to be more narrow (intra). The partial form of functional integration gave an effect on the existence of space with global functional integration, but conversely the existence of the space with global functional integration had not been able to influence the conditions of spaces with partial functional integration.

In the perspective of operational hybrid aspect, the condition of settlements in the site location with a high level of density and limited open space caused the activities of the residents in a more dynamic site location by utilizing open spaces in the circulation path as a space of interaction in formal activities and informal activities. This condition triggered conflicts between conventional use of space, and influences the realization of spatial negotiations in the site location, with the formation of private spaces (with informal activities) due to the residents' activities in utilizing them. In the perspective of hybridity in general, this condition illustrated the high level of complexity of spatial use with more varied spatial flexibility, this condition was a potential for good hybridity quality, but this condition raised problems for settlement conditions that were not organized and seem chaotic.

In the perspective of spatial hybrid, the condition of accessibility in site location was reflected through the level of achievement of spaces in site location globally and the level of comfort and security of the space users globally that were included in the "medium" category, this condition provided opportunities to increase regional space accessibility globally which also had a positive influence on improving operational aspects of hybrid and also hybrid programming in the site location. Another aspect which was a very influential factor on the quality of hybridity in the spatial hybrid perspective was the syntax value of the site configuration pattern, where in the existing condition of the site configuration pattern already had an intelligibility syntax value that was included in the good category, but it still had the opportunity to an increase in the value of the intelligibility syntax to even better.

The consolidation efforts to settlement patterns with a hybrid concept approach were basically the establishment of good spatial hybrid conditions, so that it became the basic framework for developing hybrid operational and hybrid programming. The strengthening of spatial hybrid elements by forming residential space configuration patterns that had high intelligibility syntax values illustrated the existence of good regional spatial clarity, this became positive projection of the quality of the high level of intensity of the space users and was spread out in regional space more evenly, with a better level of achievement of global space, and better accessibility to global space. A good spatial hybrid condition also allows for the formation of integration of functions that are not only oriented to certain spaces within the residential areas, but are more evenly distributed globally. 


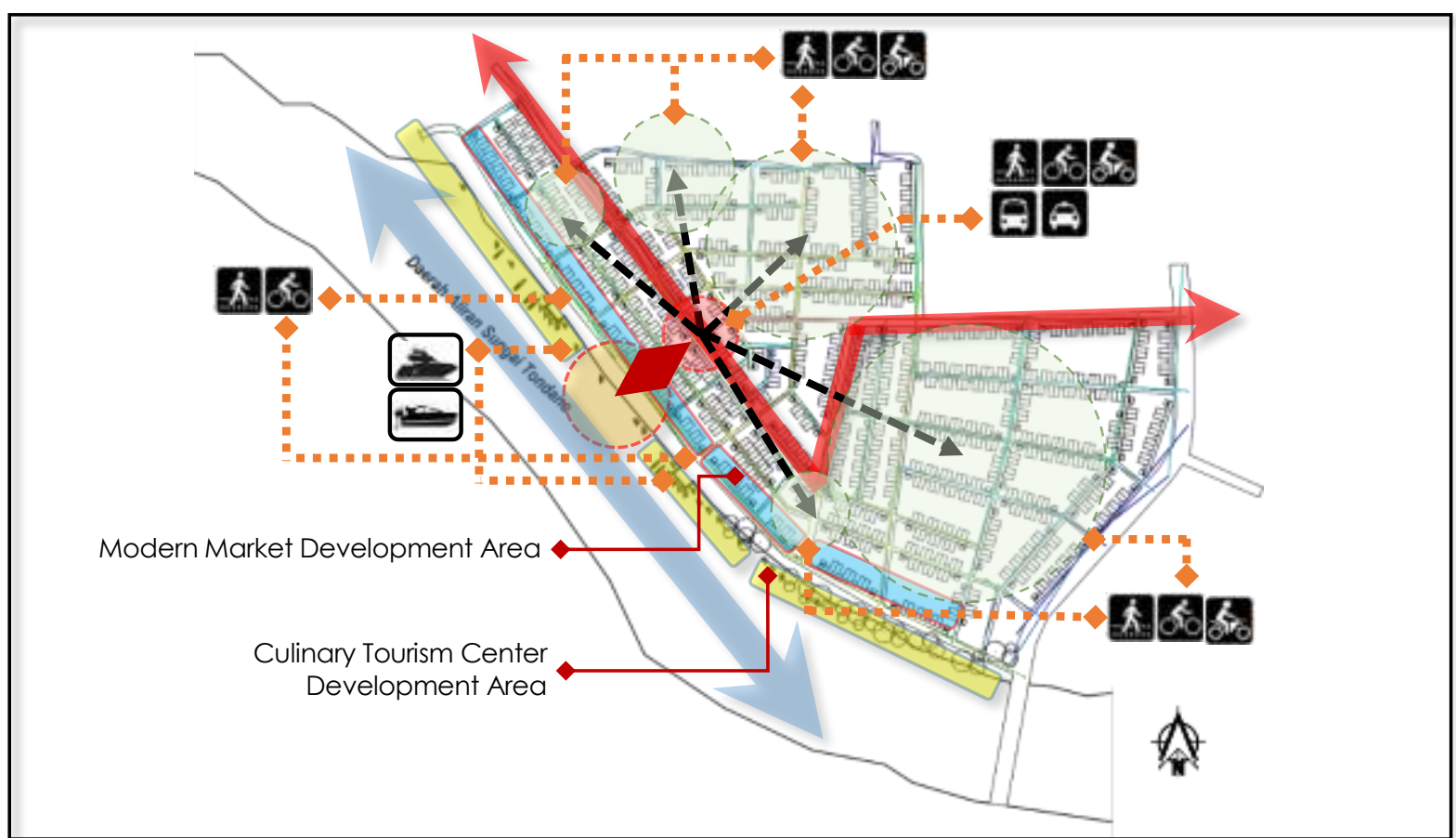

Fig. 17. Model recommendation for the structuring the transportation system and mobility, and the development of regional functions according to the selected consolidation model of the site location (Source: Analysis, 2019).

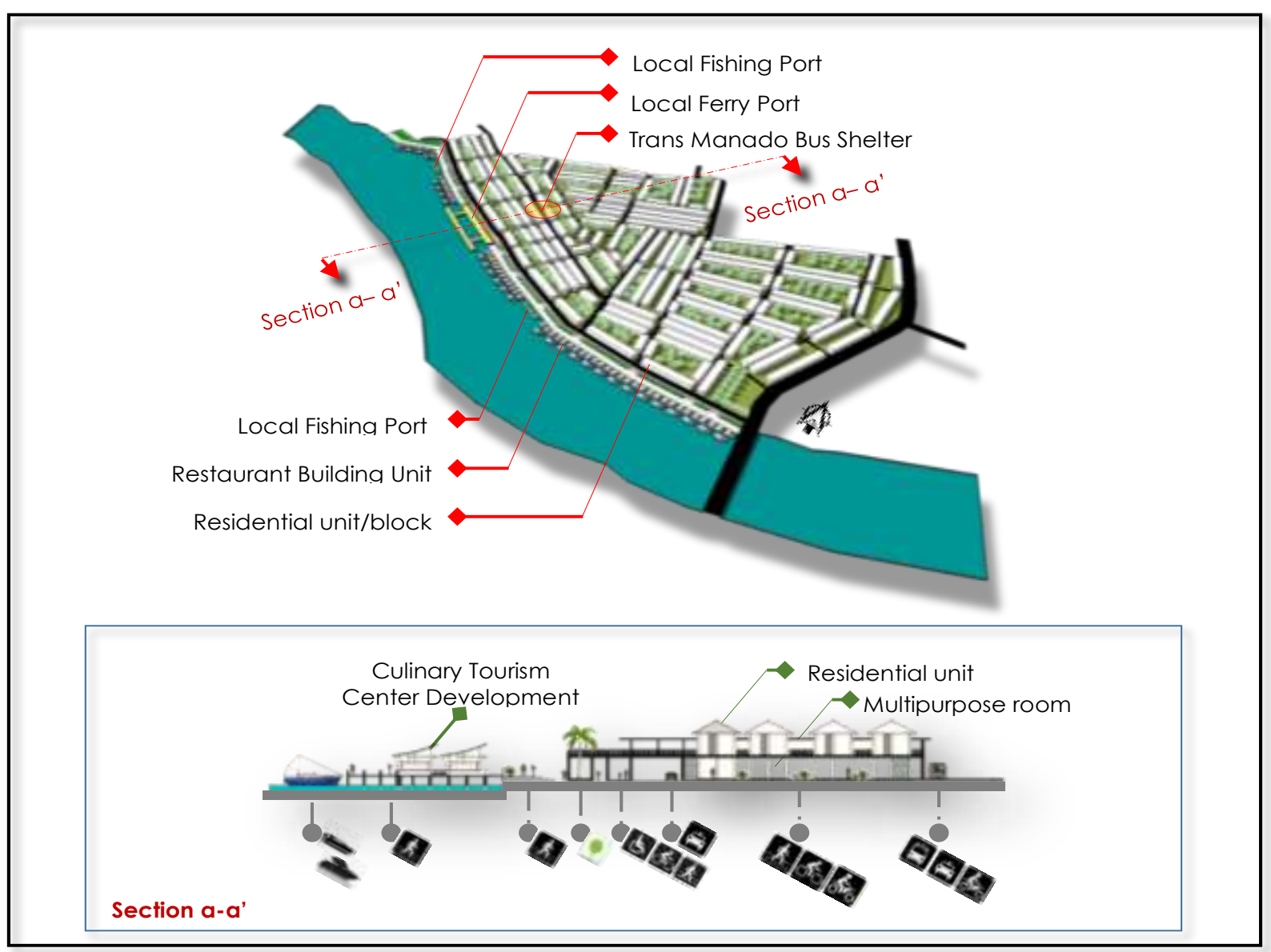

Fig. 18. Model recommendation for the structuring the transportation system and mobility, and the development of regional functions according to the selected consolidation model of the site location (Source: Analysis, 2019). 
With good spatial hybrid conditions, it allows for better spatial negotiations, so that they are embracing the realization of more dynamic space flexibility in accommodating the activities of the space users, as well as presenting orderly and conducive and innovative housing conditions.

\section{RECOMMENDATION}

In an effort to further improve the operational value of hybrids and the intended hybrid programming, the researcher sees several opportunities to improve the quality of hybridity on the site, with consideration related to activities within the settlement and also the form of site configuration chosen. One of the recommended concepts for addressing various potentials and problems that have been discussed previously is by developing regional branding values and also applying the TOD (transit-oriented development) concept which is considered applicable to the site consolidation pattern of the model configuration. The improvement of the area branding is done by developing the functional programs in areas that are more oriented towards economic activities and the development of tourist value within the site location. This is supported by an increase in access to the site through the transportation system engineering described in Fig. 17 and Fig. 18.

\section{REFERENCES}

Alexander, E. R. (1993). "Density Measures: A Review and Analysis". Journal of Architectural and Planning Research, 10(3), 181-202.

Amin, A. (2006). "Collective Culture and Urban Public Space", In City 12(1). 5-24.

Cheng, V. (2010). "Understanding Density and High Density", in L. Ng (ed), "Desinging High-Density Cities For Social and Environmental Sustainability". p.3-16. London: Earthscan.

Cho, I. S., Heng, C. K., \& Trinic, Z. (2016). "ReFraing Urban Space: Urban Design For Hybrid and High-density Conditions". New York: Routledge.

Dinas Komunikasi dan Informatika Pemerintah Kota Manado. (2017, May 19). Pemerintah Kota Manado. Retrieved from https://manadokota. go.id/index.php /2017/05/19/mengenal-kecamatan-sario/
Fenton, J. (1985). "Hybrid Building". San Francisco: Library of Congress Catalogue Card No. 82062717.

Hillier, B. (2007). "Space is The Machine: A Configurational Theory of Architecture". London: Space Syntax, Electronic Edition.

Hillier, B dan Hanson, J. (1984). "The Social Logic of Space". Cambridge; New York: Cambridge University Press.

Kurokawa, K. (1991). "Intercultural Architecture, A Philosofy of Symbiosis". London: Academy Group Ltd. \& Khiso Kurokawa.

Malnar, J. M., \& Vodvarka, F. (2004). "Sensory Design". Minneapolis: University of Minnesota Press.

Mozas, J. (2014). "This Is Hybrid, In This Is Hybrid: An analysis of mixed-use buildings". (p. 38-41). Spainyol: $a+t$ architecture publishers.

Muhi, A. (2012). "Fenomena Pembangunan Desa". Online: http://alimuhi.staff.ipdn.ac.id/wp-content/uploads/2012/06/FENOMENA-PEMBANGUNAN-DESA.pdf. (diakses 27 Juni 2018)

Nugroho, A. C. (2010). "Spatial Enclosure Sebagai Dasar Penataan Kampung Kota". Jurnal Arsitektur Universitas Bandar Lampung, 1(1). 26-28.

Prayitno, B. (2012). "An Analysis on Spatial Permeability and Fluida Dynamics of Wind and Termal in Tropical Riverside settlement areas of Banjarmasin City, Indonesia". Jurnal Manusia dan Lingkungan, 20(2).

Prayitno, B. (2013). "An analysis of Consolidation Patterns of Kampong Alley Living Space in Yogyakarta, Indonesia". Journal of Habitat Enginering and Design, 5(1). 99-112.

Prayitno, B. (2017). "Integrated Sustainable Kampong Hybrid in Code Riverside Settlement in Yogyakarta, Indonesia". $3^{\text {rd }}$ International Conference on Engineering of Tarumanagara "Smart Engineering for Future Cities". Jakarta, 04-05 October 2017. Jakarta-Indonesia. p.40-49

Prayitno, B. (2017). "Hybrid Cityblock Development, Sustainable Habitat". Engineering: The Architecture of Engineering and Policy, Pusperkim UGM. Yogyakarta.

Uytenhaak, R.,. Mensink, J,. \& Melet, E. (2008). "Cities Full of Space: Qualities of Density". Rotterdam: 010 Publisher.

Zahn, M. (1999). "Perancangan Kota Secara Terpadu: Teori Perancangan Kota dan Penerapannya". Yogyakarta: Kanisius. 